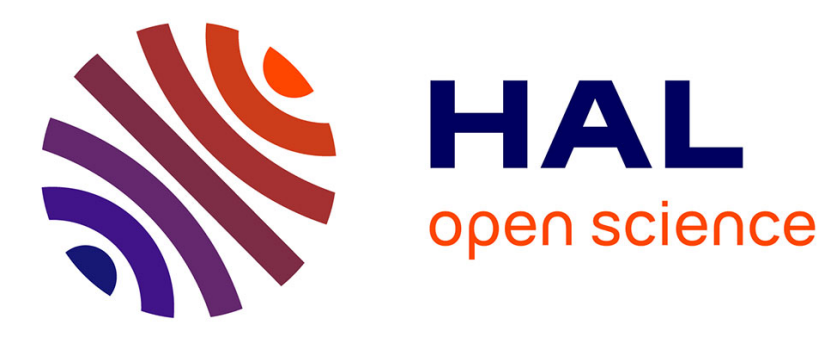

\title{
Diamond/ZnO/LiNbO3 structure for packageless acoustic wave sensors
}

Cécile Floer, Mohammed Moutaouekkil, Florian Bartoli, Harshad Mishra, Stefan Mcmurtry, Sami Hage-Ali, Omar Elmazria, Abdelkrim Talbi, Olivier Bou Matar, Damia Dekkar, et al.

\section{To cite this version:}

Cécile Floer, Mohammed Moutaouekkil, Florian Bartoli, Harshad Mishra, Stefan Mcmurtry, et al.. Diamond/ZnO/LiNbO3 structure for packageless acoustic wave sensors. IEEE Sensors, Oct 2017, Glasgow, United Kingdom. 10.1109/ICSENS.2017.8234393 . hal-01628938

\section{HAL Id: hal-01628938 https://hal.science/hal-01628938}

Submitted on 30 Jan 2018

HAL is a multi-disciplinary open access archive for the deposit and dissemination of scientific research documents, whether they are published or not. The documents may come from teaching and research institutions in France or abroad, or from public or private research centers.
L'archive ouverte pluridisciplinaire HAL, est destinée au dépôt et à la diffusion de documents scientifiques de niveau recherche, publiés ou non, émanant des établissements d'enseignement et de recherche français ou étrangers, des laboratoires publics ou privés. 


\section{Diamond $/ \mathrm{ZnO} / \mathrm{LiNbO}_{3}$ structure for packageless acoustic wave sensors}

\author{
Cécile Floer, Mohammed Moutaouekkil, Florian \\ Bartoli, Harshad Mishra, Stefan Mc Murtry, Sami \\ Hage-Ali, Omar Elmazria \\ Institut Jean Lamour UMR 7198 \\ Université de Lorraine - CNRS \\ Nancy, France \\ cecile.floer@univ-lorraine.fr \\ Abdelkrim Talbi, Olivier Bou Matar \\ Joint International Laboratory LIA LICS/LEMAC \\ IEMN UMR CNRS 8520 \\ ComUE Lille Nord de France, ECLille \\ Villeneuve d'Ascq, France
}

\author{
Damia Dekkar, Benoit Baudrillart, Fabien Bénédic \\ LSPM - CNRS, UPR 3407 \\ Université Paris 13, Sorbonne Paris Cité \\ Villetaneuse, France \\ Sergei Zhgoon \\ National Research University "MPEI" \\ Moscow, Russia \\ Florian Bartoli, Thierry Aubert \\ LMOPS EA 4423 \\ CentraleSupélec - Université de Lorraine \\ Metz, France
}

\begin{abstract}
This paper studies the Diamond/ZnO/LiNbO structure, numerically and experimentally, as a candidate for a packageless sensor based on the surface acoustic wave technology. The structure is compared with an $\mathrm{AIN} / \mathrm{ZnO} / \mathrm{LiNbO}_{3}$ structure, in order to highlight better performances of diamond with respect to AIN. Early experimental results of nanocrystalline diamond growth on $\mathrm{ZnO} / \mathrm{Si}$ are presented.
\end{abstract}

Keywords-packageless sensor; waveguiding layer acoustic wave; diamond

\section{INTRODUCTION}

Surface acoustic wave (SAW) technology is mainly known in mobile communications [1,2]. The devices used are relatively small, simple, robust and also have the advantage of being passive (batteryless) and remotely searchable (wireless). The major disadvantage of these devices comes from the package. This hermetic enclosure, which is useful to protect the SAW device from external perturbations is also bulky and costly. A packageless structure is thus highly desirable to introduce SAW devices in new fields such as the biomedical domain. For example, it will allow the monitoring of the human body's parameters due to the close proximity between the sensor and the target i.e. the skin. The bottleneck of the packaging can be solved with the concept of Waveguiding Layer Acoustic Wave (WLAW) [3,4]. The principle is based on wave confinement in a low acoustic velocity layer enclosed between two high velocity materials. The upper layers will play the role of the package by protecting the wave from external perturbations. Moreover, one of the layers has to be piezoelectric to allow the generation of the acoustic wave. $\mathrm{ZnO}$ is a material with a low propagation speed and with interesting piezoelectric properties [5]. Diamond has a very high propagation velocity $[5,6]$ so that the ideal structure would be: Diamond/ZnO/Diamond. However, $\mathrm{ZnO}$ deposition is planned as a thin layer with a sputtering process,

This work was supported by Direction Générale de l'Armement (DGA), the Région Lorraine, the European funds FEDER, the French PIA project "Lorraine Université d'Excellence" (ANR-15-IDEX-04-LUE) and the Ministry of Science and Education of Russian Federation 8.6108.2017/6.7. so it will be difficult to obtain a single crystal in order to minimize the acoustic propagation losses. It is therefore better to choose a piezoelectric single crystal substrate. $\mathrm{LiNbO}_{3}$ is a good candidate, thanks to its extremely low acoustic propagation losses, its high electromechanical coupling coefficient $\left(\mathrm{K}^{2}\right)$ and its high velocity compared to $\mathrm{ZnO}[5,7]$. Nevertheless, up to now, the high deposition temperature of diamond films has prevented the processing of the structure Diamond $/ \mathrm{ZnO} / \mathrm{LiNbO}_{3}$ since conventional piezoelectric materials lose their piezoelectric properties at high temperature [8]. As an alternative to diamond, a sputtered AlN film as top layer has already been tested [9] due to its relatively high acoustic velocity [10]. A WLAW device operating at $868 \mathrm{MHz}$ was fabricated based on a $\mathrm{AlN}(6 \mu \mathrm{m}) / \mathrm{ZnO}(2 \mu \mathrm{m}) / \mathrm{LiNbO}_{3}$ structure and the confinement of the wave was obtained from a thickness of $6 \mu \mathrm{m}$ of AlN. This previous work shows that in this case the wave mainly propagates in the $\mathrm{ZnO}$ layer. Therefore, the acoustic losses during propagation are increased, due to the relatively low crystalline quality of sputtered $\mathrm{ZnO}$ film. Recently, a low temperature process for nanocrystalline diamond (NCD) deposition has been developed [11]. This process opens a new path for high performance WLAW structures based on diamond.

This paper investigates the potential of the Diamond $/ \mathrm{ZnO} / \mathrm{LiNbO}_{3}$ structure for packageless sensing applications. The Diamond $/ \mathrm{ZnO} / \mathrm{LiNbO}_{3}$ structure will be studied theoretically and experimentally and the results compared to those of $\mathrm{AlN} / \mathrm{ZnO} / \mathrm{LiNbO}_{3}$.

\section{MATERIALS AND MethodS}

\section{A. FEM modeling}

Both Diamond $/ \mathrm{ZnO} / \mathrm{LiNbO}_{3}$ and $\mathrm{AlN} / \mathrm{ZnO} / \mathrm{LiNbO}_{3}$ structures were studied using a 2D-FEM model (COMSOL Multiphysics). A geometry with a width of $\lambda / 2$ was used and periodic conditions have been applied in order to represent the 
entire structure. The thicknesses of the substrate and the $\mathrm{ZnO}$ layer were fixed to $20 \mu \mathrm{m}$ and $2 \mu \mathrm{m}$, respectively. The thickness of the top layer was modified during the simulations. Particle displacements (due to the propagation of the wave in the material) were then computed in order to compare the wave confinement. And hence, a sufficient thickness for the upper layer was determined to have the wave confinement. Once the thickness of the top layer is known and fixed, the $\mathrm{K}^{2}$ value was calculated with respect to the $\mathrm{ZnO}$ thickness to determine the best compromise between the electromechanical coupling and propagation losses that affect the quality factor of the device.

\section{B. Experimental part}

RF magnetron sputtering was used to deposit an $\mathrm{Al}(150 \mathrm{~nm})$ layer on a $\mathrm{LiNbO}_{3} 128^{\circ} \mathrm{Y}$-cut substrate (MTI Corporation). Interdigital transducers (IDT) defined with $\lambda=4.4 \mu \mathrm{m}$ have been designed from a positive resist and an electron beam lithography process. More precisely, the structure of the IDT is done with 100 finger pairs at the center and 200 fingers on each side. The metallization ratio is fixed to $60 \%$ which impose the width of the finger $(1.32 \mu \mathrm{m})$. The aperture is also set at the value of $269 \mu \mathrm{m}$ (see Fig. 1). Chemical etching and a removing process for the resist were used to finalize the IDT manufacturing. $\mathrm{ZnO}$ was deposited using $\mathrm{RF}$ magnetron sputtering with the following parameters: 4-inch $\mathrm{ZnO}$ target, $170^{\circ} \mathrm{C}, 150 \mathrm{~W}, 6 \times 10^{-3}$ mbar, $6 \mathrm{sccm} \mathrm{O}_{2}$ and $6 \mathrm{sccm} \mathrm{N}$.

NCD films were deposited using a Distributed Antenna Array (DAA) microwave system operating in $\mathrm{H}_{2} / \mathrm{CH}_{4} / \mathrm{CO}_{2}$ (96.4:2.6:1) gas mixture under $0.25 \mathrm{mbar}$ and $3 \mathrm{~kW}$ at $250^{\circ} \mathrm{C}$ substrate temperature (see Fig. 2). The morphology and the thickness of the diamond films were investigated by scanning electron microscopy (SEM) and reflectometry, respectively. Xray diffraction (XRD) and Raman spectroscopy were carried out to estimate the microstructure of the diamond layer grown on $\mathrm{ZnO}$. Finally, SAW devices were characterized using a probe station and a vector network analyzer (VNA Agilent N5230A).

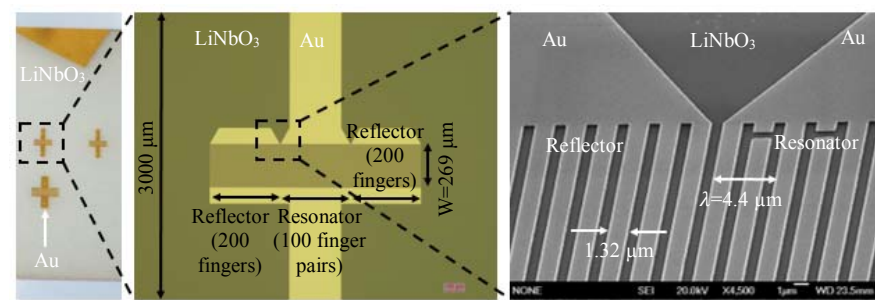

Fig. 1. Top view of microfabricated SAW devices: IDT(Ti/Au)/LiNbO ${ }_{3}$. Here, in order to allow a slightly larger diamond deposition temperature, the IDT were made of gold instead of aluminum.

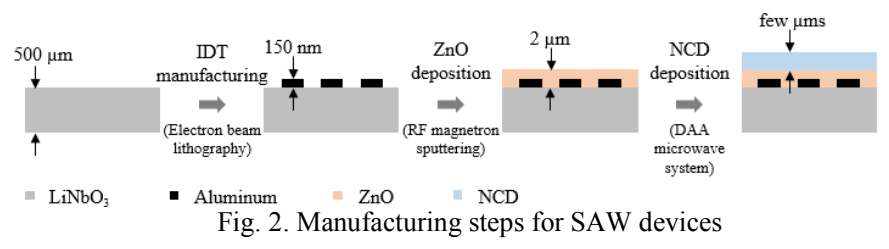

Fig. 2. Manufacturing steps for SAW devices

\section{RESULTS AND DISCUSSIONS}

\section{A. FEM modeling}

Based on a previous study [9], the confinement of the acoustic wave is obtained with a thickness of $6 \mu \mathrm{m}$ of AlN when the $\mathrm{ZnO}$ thickness is fixed to $2 \mu \mathrm{m}$. While using diamond instead of AlN, a thinner layer is required to achieve the confinement. Indeed, $2.5 \mu \mathrm{m}$ of diamond are sufficient to confine the wave (see Fig. 3). The confinement appears much rapidly with diamond due to its exceptional hardness. More precisely, the confinement is proved with the very limited displacement at the surface of the WLAW structure (see Fig. 4). Therefore, the structure Diamond $/ \mathrm{ZnO} / \mathrm{LiNbO}_{3}$ can be used for packageless applications.

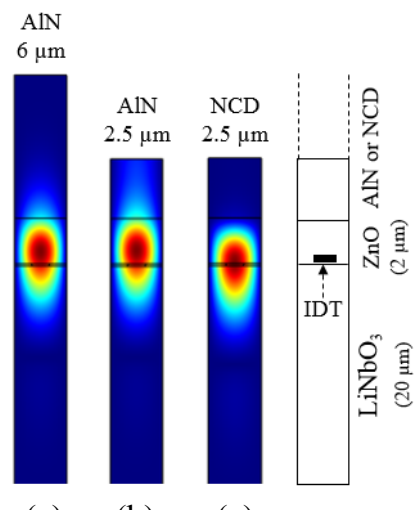

(a)

(b)

(c)

Fig. 3. 2D COMSOL modeling of particle displacements in a $\mathrm{LiNbO}_{3} / \mathrm{ZnO}$ structure with, (a) $6 \mu \mathrm{m}$ of AlN, (b) $2.5 \mu \mathrm{m}$ of AlN and (c) $2.5 \mu \mathrm{m}$ of diamond on top of it, respectively.

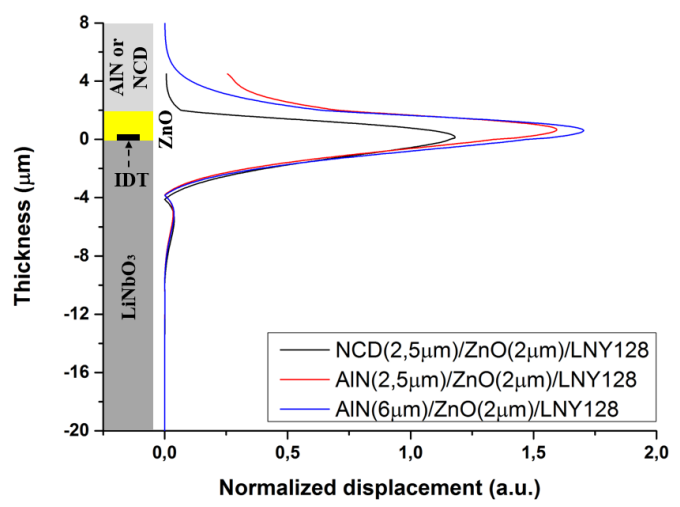

Fig. 4. 1D COMSOL modeling of particle displacements in a $\mathrm{LiNbO}_{3} / \mathrm{ZnO}$ structure with AlN or diamond on top of it.

Compared to the AlN case, with the diamond layer, the maximum deformation is shifted to the substrate. The wave tends to propagate more in the low loss single crystal $\mathrm{LiNbO}_{3}$, rather than in the $\mathrm{ZnO}$ (see Fig. 3c vs 3a), thus reducing the acoustic propagation losses and improving performance.

With the fixed value of $2.5 \mu \mathrm{m}$ of diamond, the $\mathrm{ZnO}$ layer has been optimized to maximize the wave deformation in the substrate with a reasonable $\mathrm{K}^{2}$ value. A thickness of $1.2 \mu \mathrm{m}$ of $\mathrm{ZnO}$ is suitable because the main portion of the energy of the wave propagates in $\mathrm{LiNbO}_{3}$ (see Fig. 5) and the 
electromechanical coupling factor value remains relatively high $\left(\mathrm{K}^{2}=3.9 \%\right)$.

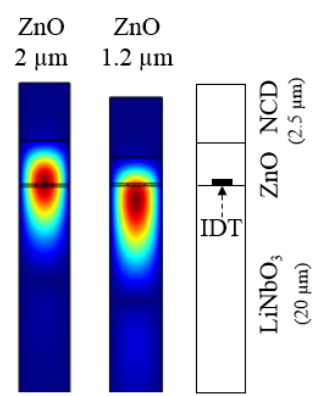

Fig. 5. 2D COMSOL modeling of particle displacements in $2 \mu \mathrm{m}$ and $1.2 \mu \mathrm{m}$ of $\mathrm{ZnO}$, respectively.

\section{B. Experimental part}

Preliminary NCD deposition experiments on $\mathrm{ZnO} / \mathrm{Si}$ substrates are promising. Indeed, the SEM pictures (see Fig. 6) showed that NCD layer can be grown on relatively rough $\mathrm{ZnO}$ surface. The Raman spectrum (see Fig. 7) exhibiting an intense peak at $1332 \mathrm{~cm}^{-1}$ also confirms that diamond is deposited on the considered samples. The diamond deposition on $\mathrm{ZnO} / \mathrm{LiNbO}_{3}$ structures and on entire SAW devices, including IDT, are in progress.
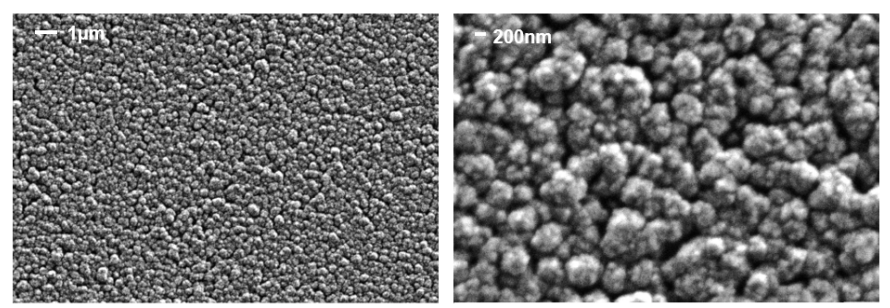

Fig. 6. SEM top view of the Diamond/ZnO/Si structure

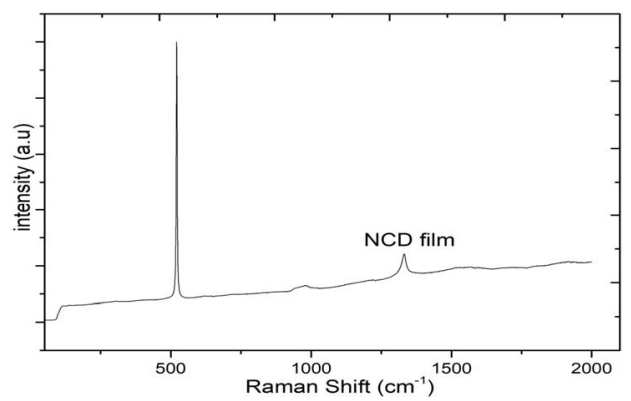

Fig. 7. Raman spectrum of a Diamond/ZnO/Si structure

\section{CONCLUSION AND PERSPECTIVES}

The comparison between the Diamond $/ \mathrm{ZnO} / \mathrm{LiNbO}_{3}$ and the $\mathrm{AlN} / \mathrm{ZnO} / \mathrm{LiNbO}_{3}$ structures has shown that the wave confinement is done more rapidly with the diamond layer than with the AIN layer. In other words, the minimum diamond thickness required for confinement is significantly lower than that of AlN. Moreover, with the diamond layer, the wave propagation tends to take place in the substrate which is a single crystal and therefore the propagation losses are reduced.

The first experimental diamond growth tests on $\mathrm{ZnO}$ layers, backed by Raman measurements, are promising.

As a short-term perspective, the aim is to prove that the Diamond/ZnO/LiNbO 3 structure can be used for packageless applications. This could be proved with the wave confinement by measuring S-parameters of the SAW sensor with and without an absorber. The Solaris elastomer, with almost the same properties as the skin, will be used as absorber as in [9]. The structure could then be validated for biomedical applications.

\section{ACKNOWLEDGMENT}

The authors would like to thank Laurent Badie and Gwladys Lengaigne at Minalor platform at Institut Jean Lamour for their help in the microfabrication.

\section{REFERENCES}

[1] C.K. Campbell, Surface Acoustic Wave devices for mobile and wireless communications, San Diego: Academic Press, 1998.

[2] S. Zhgoon, A. Shvetsov, K. Bhattacharjee, O. Legrani, P. Pigeat, and O. Elmazria, "Monitored vacuum deposition of dielectric coatings over surface acoustic wave devices," Vacuum, vol. 116, pp. 1-6, 2015.

[3] L. Le Brizoual, O. Elmazria, S. Zhgoon, A. Soussou, F. Sarry, and M. Abdou Djouadi, "AlN/ZnO/Diamond Waveguiding Layer Acoustic Wave structure: theoretical and experimental results," IEEE Trans. Ultrason. Ferroelectr. Freq. Control, vol. 57, 2010.

[4] S. Hage-Ali, O. Elmazria, G. Pierson, R. Kouitat, M. Deroh, F. Bartoli, T. Aubert and A. Talbi, "Packageless acoustic wave sensors for wireless body-centric applications", IEEE SENSORS 2016, pp.1-3, 2016.

[5] H. Nakahata, K. Higaki, S. Fujii, A. Hachigo, H. Kitabayashi, K. Tanabe, Y. Seki and S. Shikata, "SAW devices on diamond", IEEE Ultrasonics Symposium Proc., pp. 361-370, 1995.

[6] K. Yamanouchi, N. Sakurai and T. Satoh, "SAW propagation characteristics and fabrication technology of piezoelectric thin film/diamond structure", IEEE Ultrasonics Symposium, pp. 351-354, 1989.

[7] Y. Fujishima, T. Nishida, M. Shimizu and T. Shiosaki, "Growth and guided optical and surface acoustic wave properties of $\mathrm{LiNbO}_{3}$ thin films", IEEE Ultrasonics Symposium, pp. 263-266, 1993.

[8] O. Elmazria and T. Aubert, "Wireless SAW sensor for high temperature applications: Material point of view", Proc. of SPIE, vol. 8066, 806602, 2011.

[9] C. Floer, M. Moutaouekkil, F. Bartoli, H. Mishra, S. Hage-Ali, S. Mc Murtry, P. Pigeat, T. Aubert, O. Bou Matar, A. Talbi, S. Zhgoon and O. Elmazria, "AlN/ZnO/LiNbO ${ }_{3}$ packageless structure as a low-profile sensor for on body applications", to be presented at IEEE International Ultrasonics Symposium (IUS), Sept. 6-9 2017, Washington D.C. USA.

[10] T. Aubert, O. Elmazria, B. Assouar, E. Blampain, A. Hamdan, D. Genève and S. Weber, "Investigation on AlN/Sapphire piezoelectric bilayer structure for high-temperature SAW applications", IEEE Trans. Ultrason. Ferroelectr. Freq. Control, vol. 59, pp. 999-1005, 2012.

[11] B. Baudrillart, F. Benedic, A. Melouani, F. Oliveira, R.Silva and J. Achard, "Low-temperature deposition of nanocrystalline diamond films on silicon nitride substrates using distributed antenna array PECVD system”, Physica Status Solidi A, vol. 213, pp. 2575-2581, 2016. 